\title{
AC 2007-3075: THE FISHING VESSEL STABILITY EDUCATION PROGRAM: AN INFORMED BLUEPRINT FOR PROGRAM DESIGN
}

\section{Barb Howe, FishSafe B.C.}

Barb Howe started in the Canadian commercial fishing industry in the 1970s after completing a B.A. in English (18th Century) at the University of Colorado and University of Edinburgh. She has worked in other sectors of the marine industry, and holds a Canadian O.N.I Certificate (Hometrade Master unlimited tonnage, Chief Officer Foreign Going). Barb instructed at the Pacific Marine Training Institute in Vancouver, B.C. for several years, and became self-employed as Quinte Marine Services Ltd. in 1996. During her time at the Marine Institute she became interested in how people learn, and completed a M.Ed.(adult education) from the University of British Columbia in 1999. Barb works now doing vessel deliveries, most recently part of the delivery crew for a 120' tug boat from Vancouver to Trois-Rivieres near Montreal. For the last year and a half she has been the educational consultant to Fish Safe, designing the course and mentoring fishermen/facilitators for the Fish Safe Stability Education Program.

\section{Gina Johansen, Fish Safe}

Gina Johansen is a familiar personality in the B.C. fishing industry. She grew up a third generation fisherman, and raised her two children on board a seine boat. Since 1992 she has operated her project management business providing marketing and quality programs for seafood associations such as the B.C. Salmon Marketing Council. She took the position of B.C. Fishing Industry Safety Coordinator in 2003. The Fish Safe Stability Education Program for fishermen is dedicated to her Father and crew who were lost when his vessel capsized in 1975. Gina's hope is that ultimately fishermen will take ownership of safety and that there will be less tragedy in the fishing industry. As Fishing Industry Safety Coordinator she works with Provincial and National agencies who all have regulatory madates for the fishing industry. 


\title{
Fishing Vessel Stability Education Program An Informed Blueprint for Program Design
}

\begin{abstract}
A fishing vessel capsizes and the call for stability education resumes, suggesting that past and current training programs are not contributing significantly to education and prevention of capsizings. This paper introduces an industry driven educational program where fishermen's prior experience is central to their learning. Instructional design is problem based and includes a hands on model. The program, informed by research literature on learning, is described within the framework of an adult education planning model, including epistemology, needs assessment, learning outcome, instructional design, facilitation and evaluation. It was recently awarded the Canadian Society of Safety Engineers Annual Achievement Award. Pedagogical similarities with the Carl Wieman Science Education Initiative, an innovative program to reshape science education are noted. The paper concludes with a brief discussion of implications and limitations.
\end{abstract}

\section{Introduction}

Fishermen untie the lines and put to sea with the promise of a good catch and a safe return home to their family and friends. Tragically, numbers tell another story. The Transportation Safety Board of Canada (TSB) investigates marine occurrences, and their statistics indicate that since 1993 over 500 Canadian fishing vessels have been lost and more than 200 fishermen did not come home. The Workers Compensation Board of British Columbia (WCB) recently issued a media release that reports 157 fishing vessels have capsized and 66 lives have been lost in British Columbia since 1975.

Each time a fishing vessel capsizes there is a renewed call for stability training. The fishing community mourns, fishermen talk among themselves about what happened, insurance companies pay out claims, and the agencies responsible for safety training revisit the conundrum of why fishermen don't seem to be getting the safety message about stability.

In 1975 ten vessels capsized with 14 fatalities during the B.C. herring fishery. The West Coast Fishing Casualties Investigation Report recommended that seamanship training and education in stability should commence immediately to help crews become aware of the limitations of their vessels. ${ }^{1}$

In 1995 the Canadian fishing vessel Pacific Bandit capsized. The TSB recommended that the "Department of Transport...immediately undertake a safety promotion program for operators and crews of small fishing vessels to increase their awareness of the effects of unsafe operating practices on vessel stability". ${ }^{2}$ Transport Canada (TC) indicated that they had done a study that "recognized the relationship between education, awareness, positive safety attitudes and changed behaviors" The findings also noted that to reach the appropriate audience "effective means of delivering the safety message be utilized" [italics added]. ${ }^{3}$ 
In 1997 the Pacific Charmer capsized and two fishermen perished. A paper presented at SARSCENE '99 suggested that educators should focus on the way people construe the world differently, and develop educational concepts and processes tailored to the multiple realities inhabited by fishermen. The author noted that educational programs for fishermen need to use techniques that make use of learners' backgrounds and experience. Also, education for fishermen should be participatory and include active collaboration with learners, and ideally fishermen should run the programs. ${ }^{4}$

Five people perished when the Cap Rouge II capsized in 2002. The TSB Marine Investigation Report suggested that a stability education program for fishermen should follow good practices of adult education and "employ educational techniques which are most likely to impart useful knowledge to operators". At the Coroner's Inquest held following the capsize of the Cap Rouge II, the skipper's words are insightful. He testified that the TC Fishing Vessel Master IV certification course had little information about fishing vessel stability, concentrated on loading deep sea vessels, and was taught by an instructor who lectured, and had no fishing experience. One of the recommendations from the Coroner's Inquest was that Fishing Master certification should include ship stability theory and free surface principles taught in a manner that is practical and understandable for fishermen. ${ }^{6}$

Why existing stability training and safety awareness efforts do not seem to be working is a complex problem that involves the inter-relationship between fishermen, traditional training methods, and the learning environment. More attention needs to be directed at investigating how people interact to form a learning context. ${ }^{7}$ There would seem to be little disagreement about the need for stability education and safety training. Different methodologies and solutions to better inform fishermen about fundamental principles of stability need to be explored.

\section{Fish Safe}

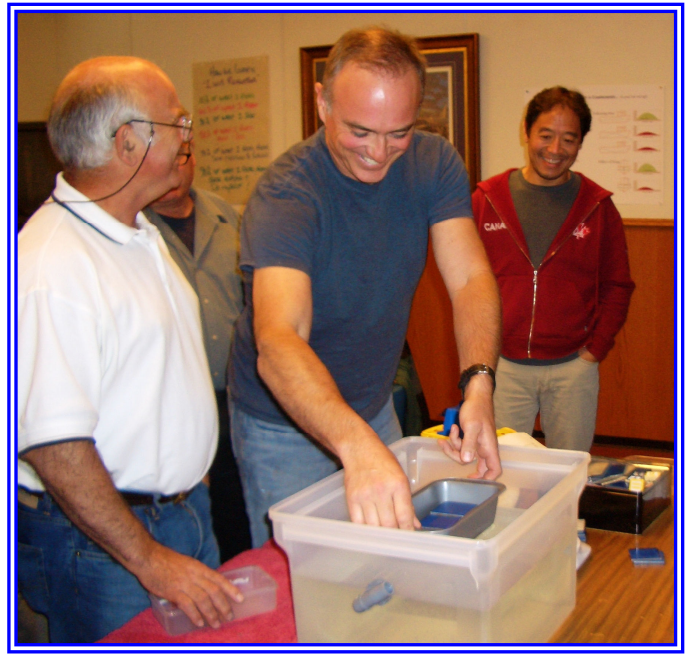

Fish Safe took on that challenge in July of 2005 when they submitted a proposal for comprehensive funding to both Transport Canada and the Workers' Compensation Board of British Columbia for the Fish Safe Stability Education Program (FSSEP). This paper describes the FSSEP in the context of an adult education program planning model, including epistemological considerations that guided instructional design. Concluding remarks address limitations and implications of the FSSEP

Fish Safe is a program developed and funded by the B.C. Seafood Alliance, and is responsible for promoting safety and health programs identified by the Fish Safe Advisory Committee. That committee actively includes fishermen, marine educators, naval architects, marine insurers, fishing companies and marine regulators with a collective mandate that fishermen will own and be responsible for safety on their vessels. Fish Safe is the responsibility of the Fishing Industry 
Safety Coordinator, and is partially funded by the B.C. Seafood Alliance in partnership with the WCB. Assessments are collected from fishermen by the WCB. This allows a portion of the assessments allocated to industry to go directly to fishermen and educational programs. An annual budget of $\$ 250,000$ has been set aside for Fish Safe over the next five years.

A proposal was submitted to Transport Canada that outlined the need to design a stability education program. In 2005 TC provided $\$ 125,000$ in funding to design a stability program, develop all instructional materials as well as to deliver and fully evaluate a pilot course that could also serve as a model for a national program.

Internationally fishing vessel safety is the responsibility of the Food and Agriculture Organization/International Maritime Organization - both part of the United Nations. A Joint FAO/IMO Working Group met to revise the Document for Guidance on Fishermen's Training and Certification, taking into account recommendations and guidelines from relevant resolutions of the 1995 STCW-F Conference (Standards for Training and Certification for Watchkeeping Fishing). The revised draft notes that "the government should make financial contributions to training schemes carried on by local government or private bodies" and that training for fishermen "should be given without charge to the trainees".

The draft also suggests that trainers should be given appropriate teacher training, and have practical fishing experience. To this end additional funding of $\$ 105,000$ from TC was secured in 2006 to train fishermen to facilitate the FSSEP, and also to subsidize the cost of delivering courses.

Following the success of the 30 hour pilot course in February 2006, ten FSSEP courses were delivered by June. At the end of January 2007, 37 courses have been voluntarily attended by over 300 commercial fishermen. Fish Safe chose four locations along the B.C. coast that made the FSSEP easily accessible to all fishermen. There is a fisherman/facilitator in each geographic area. Four tool boxes were assembled by Fish Safe that contain all course equipment including a simulation model and all facilitation resources for learning activities. This tool box format is to ensure that the FSSEP is delivered with consistency by facilitators in all locations. 


\section{Program Planning Model}

Fish Safe contracted a professional educator (M.Ed.) with twenty years experience in the commercial fishing industry and who had also instructed at the Pacific Marine Training Campus for several years. Together with the Fishing Industry Safety Coordinator, a $3^{\text {rd }}$ generation commercial fisherman, they developed the FSSEP guided by the literature and following the steps of a program planning model.

Adult Education Program Planning Model

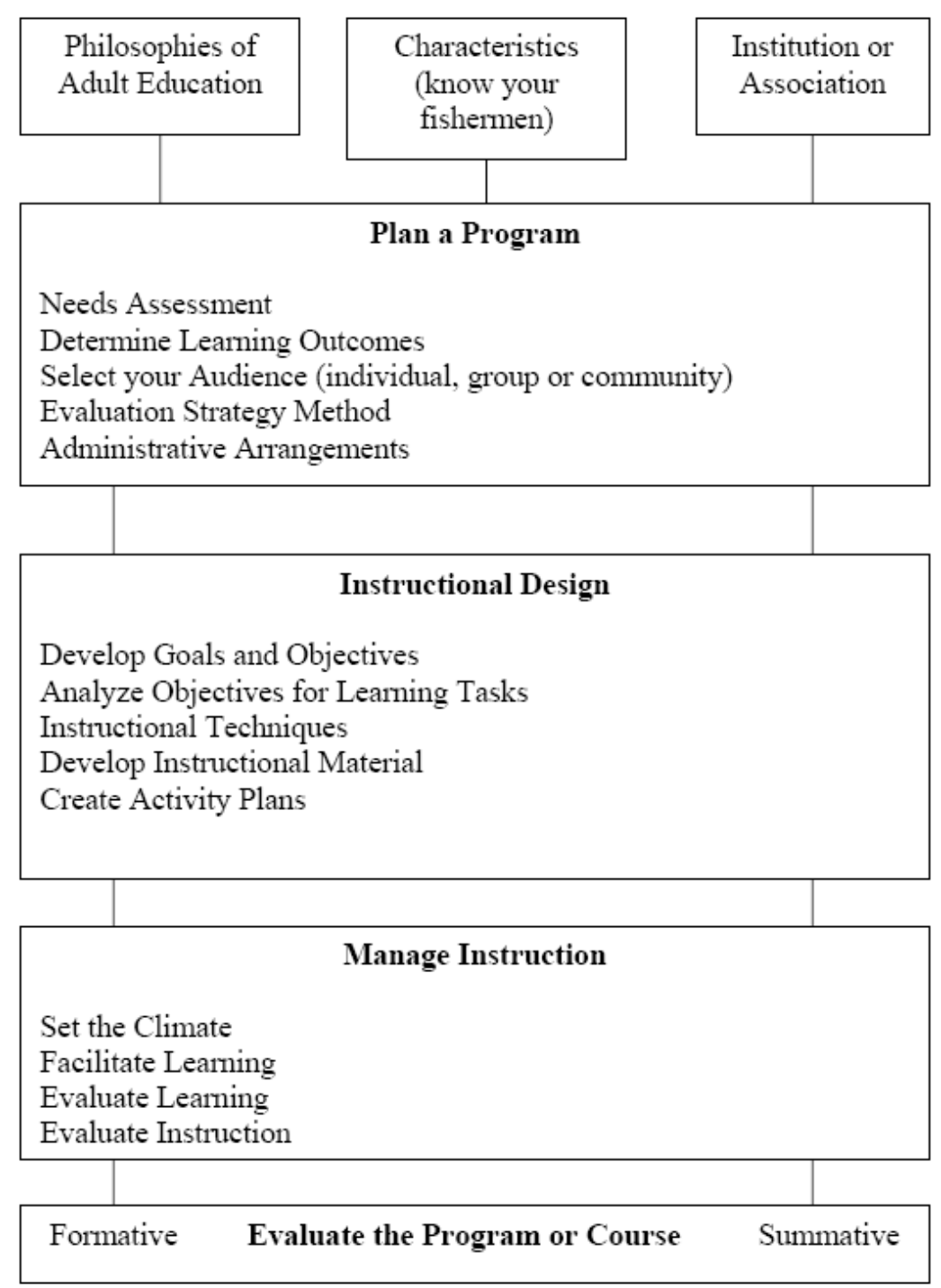

\section{Philosophies of Adult Education}

A traditional branch of philosophy is epistemology - the exploration of the nature and origin of knowledge, how we come to know things and how knowledge is possible. Traditionally, stability training has been situated in an objectivist epistemology. Briefly this position sees knowledge as disinterested fact forms independent of the individual mind. Knowledge that is 
objective can be verified by procedures such as those found in science or mathematics. Instruction is teacher centered. As the "expert" the teacher "transmits" de-contexualized knowledge and facts to essentially passive students who are expected to replicate content into operating practices. Instructional design uses lectures, text books, and work books of repetitive exercises to ensure content mastery.

In contrast, the FSSEP is anchored in a constructivist epistemology. Central to constructivism is the tenet that learning is an interactive and social process. Learners create new ways of knowing and practice by incorporating past experience and knowledge with new information. The instructor is a facilitator who coaches, mediates, prompts, and helps learners develop and assess their understanding, and thereby their learning. Constructivist learning relies on instructional design that is problem based, using group work, cooperative learning activities, critical questioning, decision making, experimental inquiry, case studies, learning games, personal narrative, and simulations to realize a pre-determined learning outcome.

\section{Needs Assessment}

Most program planning models are front end loaded with some kind of a needs analysis. ${ }^{9}$ Fish Safe did not conduct a formal needs assessment - the history of capsizings corroborates a resounding need for stability education. At an industry meeting that explained requirements of TC and the WCB with regard to regulatory stability documentation for fishing vessels, fishermen said that regulation without education was unacceptable, and asked Fish Safe to design a relevant and useful educational program on stability.

In another context the word need, as used in education program planning, has two parts that reflect a discrepancy between a present state of affairs and a description of some more desirable future state of affairs. The owner of the discrepancy is the person or group of persons who would have to act differently if the future state of affairs were to be realized. The owner of a prescriptive need is not the person or persons who would be required to change attitudes or behaviours. A motivational need is when the owner of the discrepancy perceives the need. For example, a TC mandatory safety course is a prescriptive need, whereas a voluntary course on vessel stability reflects a motivational need. The success of a program is exponential when there is total agreement between prescriptive and motivational needs, or when a program is driven entirely by motivational needs.

\section{Learning Outcomes}

The next step, following the program planning model was to determine the learning outcome. The FSSEP learning outcome for fishermen is:

You will take ownership of fundamental principles of stability, and they will be central to your every day reality when making any decision that affects your vessel's operations.

A learning outcome is a broad statement of what participants will take away from a program. Curriculum development with learning outcomes has its origins in systems theory and 
constructivism, and includes authentic assessment. In contrast, curriculum development with a content approach, is situated in liberal philosophy, and assessment is with norm referenced exams. The competency approach stems from behaviourist learning theory, and assessment is by criterion referenced competencies.

Although the FSSEP does not have any formal learning contract, the following are promises to participants that reflect a constructivist epistemology:

1. Your experience as a commercial fisherman is respected and you are encouraged to talk about your fishing experiences

2. You will be actively engaged in learning

3. You will work with real life problems related to stability and commercial fishing

4. Your questions are valuable and they will all be answered

\section{Curriculum Goals}

A curriculum goal is a general statement of what participants will learn in a course. The curriculum goals of the FSSEP are:

1. You will have a stability vocabulary that will enable you to talk about stability with personal authority

2. You will be able to read a stability data book and use the information to help you make operational decisions when fishing

3. You will appreciate the cumulative nature of threats to vessel stability

4. You will be able to write stability instructions specific to your vessel and fishing operations

Detailed activity plans with objectives and learning tasks were written. In theory, if participants can do all the learning tasks, they can do the objective. If they can do all the objectives, they can achieve a goal. If all the goals are achieved participants will complete the course, and realize the learning outcome. In practice this algorithmic approach becomes a bit blurred, however it is useful tool for organizing curriculum.

\section{Instructional Techniques}

Once curriculum goals, objectives, and learning tasks were identified, instructional techniques, grounded in constructivist theory and congruent with the learning outcome, were determined. Borich identifies two broad classifications of learning outcomes based on complexity of behaviors: ${ }^{10}$

Type 1 - Fact: $\mathrm{C}$ of $\mathrm{G}$ is where weight of ship and deadweight acts down through Rule: $\mathrm{G}$ moves towards weight added Action sequence: weight added low down lowers the $\mathrm{C}$ of $\mathrm{G}$

Type 2 - Concept: Skipper has control of $\mathrm{C}$ of $\mathrm{G}$ by how ship is loaded Pattern: $\mathrm{C}$ of $\mathrm{G}$ changes during a fishing trip Abstraction: Maintain a stable vessel through a fishing trip 
The FSSEP learning outcome is that fishermen will make fundamental principles of stability central to their everyday reality when making operating decisions, which is a Type 2 learning outcome. Type 1 learning outcomes require lower cognitive behavior and are usually taught by direct instruction, i.e. lecture. Type 2 outcomes require higher cognitive behavior and are achieved with indirect instruction where the learning process is inquiry, the result is discovery and the learning context is a problem.

\section{Indirect Instruction}

Indirect instruction is learner centred rather than teacher centred. It is problem based learning that uses case studies, cooperative learning activities, skillful questioning as learning probes, simulation, learning games, guided discussion groups - and enables participants to integrate new concepts with their prior experience to create knowledge. There is a significant amount of evidence that suggests that "learners use their current knowledge to construct new knowledge and that what they know and believe at the moment affects how they interpret new information." 11

A fictional case study is used as a pre-assessment strategy to determine participants' knowledge about stability, and TSB Occurrence Reports provide real-life case studies. Cooperative learning activities allow fishermen to explain concepts and patterns to each other, and learning games reinforce stability vocabulary by using correct terminology to advance fishing vessels on a playing board. Guided discussions where fishermen tell their own stability stories is an important part of the instructional design. Instructional techniques that do not allow participants to relate their prior experiences are often seen as irrelevant and not effective for learning, and indeed may be rejected..$^{12}$

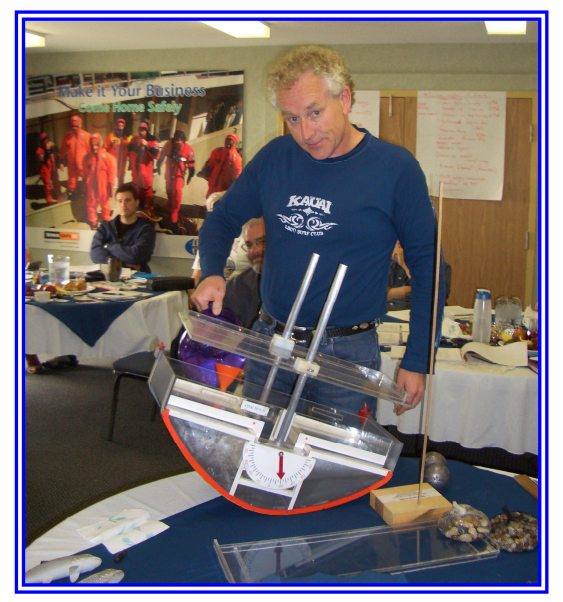

Simulation is a structured situation where learners are involved with a setting and objects that represent a real situation as much as possible. The FSSEP uses a model with crossconnected fuel tanks, which has a number of interchangeable decks with different gear configurations. A vessel originally designed for gillnetting can be modified for a trap fishery that shows the raised $\mathrm{C}$ of $\mathrm{G}$ and tendency towards tenderness or instability. There is a wheelhouse deck than can be loaded with spare gear, lockers and freezers, and a deck that shows the effect of free surface on vessel stability.

Fish Safe has produced a video/dvd called "Measuring Stability" that engages viewers in an inclining experiment to establish GM and lightship KG. Fishermen can simulate the steps of an incline with the model. An interactive handbook has been written called "Fishing Vessel Stability - Make it your Business" that contains the curriculum inter-woven with personal stability stories of survival and tragedy.

The variety of instructional techniques associated with indirect instruction are likely to appeal to a greater variety of learning styles than direct instruction with lectures. ${ }^{13}$ There is also evidence 
that indirect instruction enhances motivation to learn, in part because it draws extensively on the prior experience that participants bring to the learning environment. ${ }^{14}$

\section{Facilitation}

From the previous section on instructional techniques, the FSSEP does not use a teacher/expert who "transmits" facts, but rather a facilitator who enables and guides collaborative learning activities. Facilitating learning can be more challenging than teaching because the facilitator is always actively involved with the learners. Critically important to the success of the FSSEP is the credibility of the facilitator. ${ }^{15}$ A program runs the risk of failing without the support and involvement of fishermen, and that when possible experienced fishermen should be instructors. ${ }^{16}$

Two fishermen in the pilot course offered in February 2006, stepped up to the plate and said they would like to be facilitators. One of these fishermen was initially very resistant to integrating new knowledge, maintaining that he'd fished successfully for twenty years and that the "feel" of the boat was a sufficient indication of stability. Dispelling these kind of common myths is an important part of the FSSEP. On the third day this particular fisherman had an epiphany and is now the lead FSSEP fisherman/facilitator.

Fish Safe developed a comprehensive Facilitator's Guide with activity plans and resources that was the basis of the first Facilitator's Workshop which followed the pilot course. There have been two subsequent Facilitator Workshops, one on questioning techniques, and the most recent a technical workshop on stability KN curves. Increasing facilitators' technical knowledge about stability is important because "numerous studies demonstrate that any curriculum is mediated by a teacher's understanding of the subject". ${ }^{17}$ Facilitators mentor amongst themselves, as well as initially being mentored by the professional educator.

Brookfield explains that journals are a way for teachers to reflect on their practice. ${ }^{18}$ After each FSSEP course, facilitators complete a Facilitator's Log Book and entries are circulated to all facilitators. An audit process is also in place and identified, for example, the need for a workshop on questioning techniques. Fisherman/facilitators are remunerated by Fish Safe. They provide passion for free.

\section{Evaluation}

The FSSEP has three evaluation components; participant, formative and summative. These multiple levels are a part of responsible program planning.

There are two reasons why participant evaluation is important. The first is to let participants measure their new knowledge of stability principles and how these principles are reflected in their operating practices. The second purpose is to provide the FSSEP with data to develop a precis of results expressed as a dichotomous variable. This information is frequently required in funding proposals.

Traditional direct instruction with Type 1 learning outcomes uses multiple choice or matching type instruments that assess recall and recognition of terms and concepts. Authentic assessment 
associated with Type 2 learning outcomes situate learners as much as possible in real life situations to evaluate responses to questions about that situation.

The FSSEP participant evaluation includes both types of assessment, with particular attention to carefully designed case studies and visual clips of a variety of operating practices including scenes from "The Deadliest Catch Second Season" that documents the perilous Alaskan King Crab fishery in the Bering Sea. ${ }^{19}$ Fishermen identify potential threats to stability from the clips, and discuss basic stability principles in the context of operational practices that could mitigate risk of capsize. These situation visuals are also valuable because they allow verbal assessment of fishermen who may not read or write.

Formative and summative evaluation is done with a three part Likert rating scale that asks participants to respond to questions about their perceived mastery of the learning outcome and the four course goals. Formative responses may require action - for example, many participants did not feel that they were able to write stability instructions for their vessel. In response Fish Safe created a template for writing instructions that gives participants better guidance.

The Likert course evaluations also provide summative information that can be described statistically by determining mean responses and establishing the central tendency. Determining range or standard deviation provides a second statistical measure of variability, and gives a more detailed description of findings. This summative data is also valuable in proposals for funding.

Additional summative evaluation is part of the Fish Safe Phase II project funding proposal to TC. Using qualitative ethnographic research, it is proposed to conduct on board interviews with skippers and crew who have participated in the FSSEP and those who have not, and compare to see if the FSSEP has influenced operating practices. Confounding variables must be identified and factored into research findings.

\section{In their own words}

"Instructed by a fisherman who knows about real life" "Stability is not about the 'feel' of my boat"

"Some of the things I have done in the past were wrong, I've been lucky"

"How much I didn't know that I thought I did"

"Someone is taking our jobs as fishermen seriously and showing us respect"

"Discussion style of learning worked good"

"The interaction with others and the model helped me figure out stability"

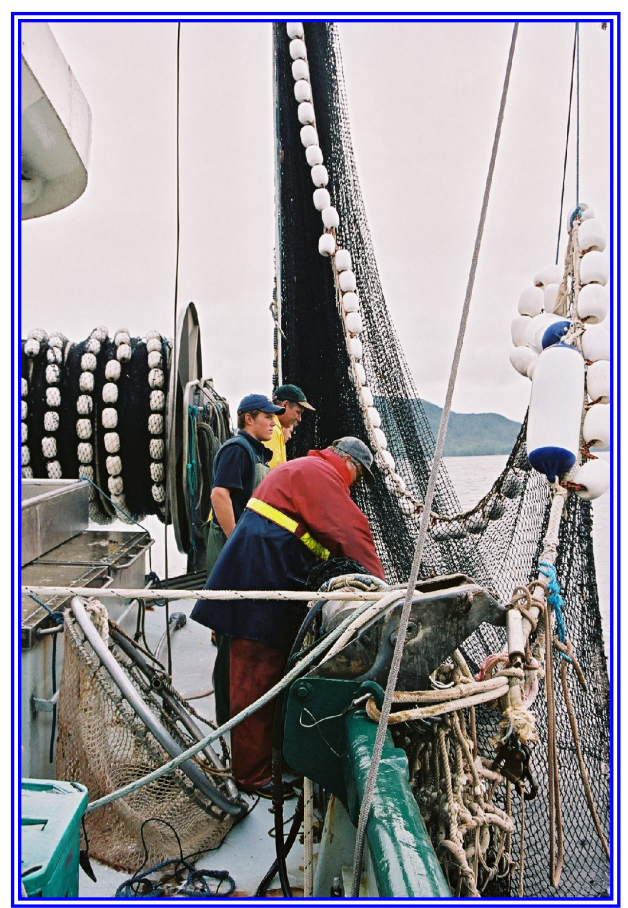




\section{Discussion}

The FSSEP has been informed by considerable research from the literature of adult education, and has emerged as a clear departure from the traditional lecture used in most marine training programs. It is of interest that the University of British Columbia has put up \$12 million over five years for the Carl Wieman Science Education Initiative. This initiative is the work of Carl Wieman, Nobel physics Laureate (2001). It is his belief that because traditional lecture lacks interaction with students, they often complete course work by memorizing facts without retaining key concepts, and remain unable to address and solve problems. ${ }^{20}$

His project emphasizes an interactive environment that values student experience, stimulates inquiry, and encourages measurement of educational outcomes from defined learning goals for specific courses. ${ }^{21}$ Part of the project includes pursuing research results on student learning, the effectiveness of different teaching methods, and instructional design that enables students to develop new ways of thinking that require extended mental effort to construct meaning.

Similarly, the FSSEP is situated in a non-traditional paradigm for learning, where rigorous program evaluation constitutes research and has the promise of informing other commercial fishing and marine programs. It has been suggested that program evaluation and educational research are intrinsically married as evaluation is the application of research skills to determine the worth of an educational practice. ${ }^{22}$

International implications include developing countries with artisan fisheries and low levels of literacy where story telling and narrative are important tools for learning. The program is easily adapted to regional fisheries to form the basis of a national program. There is significant interest in the non-traditional nature of the FSSEP. With funding from TC, East coast fishermen and educators will attend a West coast FSSEP course in mid-March 2007, followed by a one day facilitation workshop. The FSSEP has the support of marine insurers, surveyors, and the naval architect community, and recently received the Canadian Society of Safety Engineers Annual Achievement Award.

The FSSEP is aware that there are limitations particularly associated with learning transfer to actual practice. The ethnographic research described above is an evaluation approach that might possibly reveal whether learning transfer about stability has mediated operational practices. In general knowledge taught in a variety of contexts that relate to previous experience lead to greater learning transfer. ${ }^{23}$ Interactive instruction takes significantly more time to develop and maintain, which translates into higher costs. Providing technical workshops for fishermen/facilitators on a regular basis is also a cost factor. Additional funding is required to sustain this program and properly evaluate its worth, merit and results.

Any stability education program for fishermen needs to acknowledge the fact that safe stability operating practices may be challenged by the promise of significant financial gain. The FSSEP believes that with stability education, operational decisions will be based on informed risk considerations nested in fundamental principles of stability - and that all fishermen will be in a better position to come home safe to their family and friends. 


\section{Bibliography}

1. CatinusW.A.W., Bonn W.E., and Thorne B.D. (May 1975). West Coast Fishing Casualties Investigation Report. Marine Investigations Section, Ministry of Transport: Ottawa

2. Transportation Safety Board of Canada. Fishing Vessel "Pacific Bandit". Marine Occurrence Report Number M95W0005. Ottawa, p. 22.

3. Transport Canada (1996). Response to Transportation Safety Board Recommendations. http://www.tc.gc.ca/tcss/tsb/marine/1996-recs/M95W0005/EN/PACIFICBANDIT

4. Boshier, R. (1999). "Dying to Fish, Fishing to Die: Society, Culture and Accident Prevention". Paper presented at SARSCENE '99, St. Johns, Newfoundland, pp.71-73.

5. Transportation Safety Board of Canada. Fishing Vessel "Cap Rouge II". Marine Investigation Report Number M02W0147, Ottawas, p. 46.

6. British Columbia Coroner's Court, notes of evidence, given at the Inquest into the Capsizing of the Cap Rouge II, May 2004.

7. Merriam, S.B. and Caffarella R.S. (1991). Learning in Adulthood. San Francisco: Jossey-Bass, p. 40.

8. Report of the Joint FAO/ILO/IMO Working Group on Fishermen's Training (February 1999). Training and Watchkeeping. MSC 71/INF.3, pp. 15-16.

9. Kemp J.E. (1985). The Instructional Design Process. New York: Harper and Row;

Knowles M.S. (1980). The Modern Practice of Adult Education: From Pedagogy to Andragogy. ( $2^{\text {nd }}$ ed.) New York: Cambridge Books.

10. Borich, G.D. (1992). Effective Teaching Methods. New York: Macmillan, pp. 180-242.

11. Bransford, J.D., Brown, A.L. and Cocking R.R. Eds. (2000). How People Learn. Washington D.C.: National Academy Press, p. 152.

12. Guy T.C. (1999). "Culture as Context for Adult Education: The Need for Culturally_Relevant Education". New Directions for Adult and Continuing Education, T.C. Guy Ed. Number 82, Summer 1999. San Francisco: Jossey-Bass, p. 16.

13. Kolb D. (1984). Experiential Learning: Experience as the Source of Learning and Development. Englewood Cliffs, NJ: Prentice-Hall.

14. Biehler R., and Snowman J. (1997). Psychology Applied to Teaching. New York: Houghton Mifflin, pp. 399422.; Wlodkowski R.J. (1998). Enhancing Adult Motivation to Learn, a Comprehensive Guide for Teaching all Adults. San Francisco: Jossey-bass.

15. Boshier, R. (1990). "Dying to Fish, Fishing to Die: Society, Culture and Accident Prevention". Paper presented at SARSCENE '99, St. Johns, Newfoundland, pp. 71-73; Wlodkowski R.J. (1998). Enhancing Adult Motivation to Learn, a Comprehensive Guide for Teaching all Adults. San Francisco: Jossey-bass; Herbert J. (2000). "Progress in Prevention and Response in Vessel Safety", Proceedings of the International Fishing Industry Safety and Health Conference, Eds. J. Lincoln et al. NIOSH, Cincinnati, OH, p. 7.

16. Petursdottir G., Hannibalsson, O. and Turner J.M.M. (2001). Safety at Sea as an Integral Part of Fisheries Management. FAO Fisheries Circular. No. 966. Rome, FAO, p. 17.

17. Bransford, J.D., Brown, A.L. and Cocking R.R. Eds. (2000). How People Learn. Washington D.C.: National Academy Press, p. 163.

18. Brookfield, S.D. (1990). The Skillful Teacher, on Technique, Trust, and Responsiveness in the Classroom. San Francisco: Jossey-Bass, p. 192.

19. Discovery Communications Inc. (2006). Deadliest Catch Season 2. Silver Spring, MD.

20. Vancouver Sun, Friday December $1^{\text {st }}, 2007$

21. http://www.bc.net/2007-conference/keynote.htm

22. McMillan J.S. and Schumacher S. (1993). Research in Education. ( $3^{\text {rd }}$ ed.) New York: Harper Collins, p. 518.

23. Bransford, J.D., Brown, A.L. and Cocking R.R. Eds. (2000). How People Learn. Washington D.C.: National Academy Press. 